\section{FORMA OBJETIVA EM ROBERTO SCHWARZ: UM CONCEITO COMUM ENTRE A LITERATURA E O CINEMA*}

Vitor Soster*

RESUMO: A "forma objetiva" pode ser considerada como central nas análises literárias e cinematográficas de Schwarz (2012d). Revisando seus estudos e estabelecendo conexões com a contemporaneidade, este trabalho percorre discussões feitas pelo autor sobre Memórias Póstumas de Brás Cubas (Machado de Assis, 1881), "Pobre Alimária" (Oswald de Andrade, 1925), Os Fuzis (Ruy Guerra, 1964) e Terra em transe (Glauber Rocha, 1967). Após essa revisão, apontamentos são feitos a respeito de $O$ som ao redor (Kleber Mendonça Filho, 2012), buscando identificar, nessa obra, sua forma objetiva e sua dinâmica relacionada ao Brasil. Entretanto, problema local jamais é visto como desassociado do global. Logo, em direção ao final, associações são feitas com estudos do crítico norte americano Jameson (2000), especialmente no que concerne ao conceito de "mapeamento cognitivo". Pela recorrência nesses exemplos, apresenta-se, ao final, sentido pretendido por Schwarz ao se referir a certas ideias como estando fora do lugar (2012c).

PALAVRAS-CHAVE: forma objetiva; literatura; cinema; contemporaneidade; dialética. *sosterv@gmail.com

Bacharel e Licenciado em Letras (Português/Inglês) pela universidade.

ABSTRACT: The concept of "objective form" may be considered as central to Schwarz's (2012d) literary and film analysis. So in order to review some of his studies and establish some connections to the present time, this paper examines Schwarz's studies on The Posthumous Memoirs of Bras Cubas (Machado de Assis, 1881), "Pobre Alimária" (Oswald de Andrade, 1925), The Guns (Ruy Guerra, 1964) and Entranced Earth (Glauber Rocha, 1967). After that, notes on Neighboring Sounds (Kleber Mendonça Filho, 2012) are also made in search of identifying its own objective form and its dynamics that is related to Brazilian society. However, the local problem is never seen as separated from the global realm. Thus, towards the conclusion, associations are made to Jameson (2000), a North American literary critic, especially in what concerns his "cognitive mapping" concept. Therefore through the reiteration of these examples Schwarz's intended sense of the misplaced ideas (2012c) is shown.

KEYWORDS: objective form; literature; cinema; present time; Dialectics
O presente trabalho deve muito às contribuições dadas pela professora doutora Maria Elisa Cevasco em seu curso de pós-graduação "Intervenções críticas: um estudo sobre a Teoria em Roberto Schwarz e Fredric Jameson", ministrado no primeiro semestre de 2013 na Faculdade de Filosofia, Letras e Ciências Humanas da USP; além disso, agradeço também aos meus colegas de pós-graduação em Letras e Ciência Política pelas discussões no grupo "Sequências Brasileiras", que se dedica ao estudo da obra de Roberto Schwarz. 
1. SCHWARZ. Por que 'ideias fora do lugar?', p. 170

2. SCHWARZ. Por que 'ideias fora do lugar?', p. 169.
"Ideias sempre têm alguma função e nesse sentido, estão sempre no seu lugar" ${ }^{1}$. Assim diz o crítico literário Roberto Schwarz ao tratar do frequente mal entendido referente à compreensão de que ele apenas vê total incompatibilidade das ideias liberais no contexto social brasileiro do século XIX. E uma possível razão para isso é primeiramente um entendimento insuficiente do próprio raciocínio dialético do autor, que lida principalmente com as produções literárias brasileiras. Como ele mesmo afirma, "o dado de observação tem horizonte local, mas o horizonte último da análise é globalizador e ironiza o primeiro, que pode ironizá-lo por sua vez" ${ }^{2}$. Quer dizer, não se estuda a produção cultural brasileira para compreendê-la em si mesma, nem para colocá-la em pé de igualdade com a produção norte-americana e europeia; o que se propõe é o seu estudo em relação à cultura hegemônica. Isto é, se falamos numa relação de hegemonia, falamos de uma relação entre centro e periferia, desse modo conferindo relevância à esfera econômica ao tratar de questões referentes à cultura. Pode-se também estabelecer um debate sobre as manifestações culturais dos países centrais que não se apresentam portando uma superioridade absoluta, traço esse que se mostra importante para o estudo do próprio desenvolvimento do capitalismo, vista a relevância da cultura para a própria constituição e captação do poderio econômico vigente.

Assim, com o intuito de operar dialeticamente as esferas cultural e socioeconômica, o autor irá se fundamenta no conceito de forma objetiva, tal como exposto em seus "Pressupostos, salvo engano, de 'Dialética da Malandragem"” , ensaio em que discute o estudo de Antonio Candido sobre o romance de Manuel Antônio de Almeida, de 1852 Memórias de um sargento de milícias. Como afirma Schwarz, "não se trata de opor estético a social. Pelo contrário, pois a forma é considerada como síntese profunda do movimento histórico, em oposição à relativa superficialidade da reprodução documentária" ${ }^{4}$. Por esse motivo, em seus estudos, ele não irá se apegar estritamente ao enredo das narrativas, mas à forma pela qual são apresentadas. Posto isso, coloco como pontos de convergência deste trabalho o conceito de forma objetiva e o desejo de estabelecer conexões entre diferentes objetos estéticos no tocante à sua constituição histórico-social (exatamente aquilo que cada vez mais se mostra como uma difícil tarefa na contemporaneidade).

Busco, inicialmente, recuperar alguns apontamentos feitos pelo autor em Um mestre na periferia do capitalismo, publicado originalmente em 1990, em que ele se dedica ao estudo do romance machadiano Memórias póstumas de Brás Cubas de 1881; num segundo momento, dedico-me a levantar alguns aspectos de dois ensaios de Schwarz: "A carroça, o bonde e o poeta modernista" ${ }^{5}$, em que o foco de discussão é a produção modernista; e "O cinema e Os fuzis" ${ }^{6}$ em que ele analisa o filme de Ruy Guerra, produzido em 1964. Passo, num terceiro
3. SCHWARZ. Que horas são?: ensaios, p. 129-155.

4. SCHWARZ. Que horas são?: ensaios p. 135.

5. SCHWARZ. Que horas são?: ensaios, p. 11-28.

6. SCHWARZ. O pai de família e outros estudos, p. 29-36. 
7. JAMESON. Cognitive mapping, $p$. 277-287.

8. XAVIER. O olhar e a voz: a narração multifocal do cinema e a cifra da História em São Bernardo, p. 126-138. momento, a levantar algumas percepções a respeito do filme O som ao redor de Kleber Mendonça Filho, produzido em 2012, e que, como pretendo, pode ser de interesse para a discussão de certas questões da contemporaneidade e para a reafirmação da contínua precisão da forma objetiva na análise de obras artísticas. Por fim, com o intuito de destacar que o acerto do crítico brasileiro não é único, mas uma singular contribuição para uma mesma intuição que ganhou outras interpretações pelo mundo, trago alguns apontamentos do crítico norte-americano Fredric Jameson e de seu conceito de mapeamento cognitivo ${ }^{7}$ que guarda relações com o de forma objetiva.

Como breve observação introdutória, fica também a justificativa pela escolha de objetos culturais pertencentes a duas linguagens distintas. A princípio, estabelecer relações entre literatura e cinema pode parecer inadequado visto possuírem linguagens distintas. Contudo, para além das diferenças entre a linguagem verbal e a audiovisual (que certamente se relacionam de modo distinto com o mundo), o que se quer mostrar é certa recorrência em suas respectivas formas, o que nos leva a observar a existência de uma mesma realidade sócio-histórica a fundamentar a própria existência das narrativas aqui mencionadas. E mesmo no âmbito das diferenças, especialmente no que concerne à questão do foco narrativo tal como tratada por Xavier ${ }^{8}$, busco atentar para a centralidade do narrador em primeira pessoa no romance de Machado e a provável inadequação da distinção entre primeira e terceira pessoa (como fazemos na literatura) quando tratamos de narrativas audiovisuais ${ }^{9}$, o que, de todo modo, mantém a validade do conceito de forma objetiva. Pretendo, pois, retomar a existência de certa matriz colonial que formaria o romance brasileiro, o que, por sua vez, poderia pôr em perspectiva histórica as percepções de Schwarz a respeito da sociedade brasileira dos anos 60 , oferecendo-nos bons fundamentos para compreender a contemporaneidade.

Considerando, então, a relação entre a forma pela qual determinada narrativa é apresentada e seu contexto socioeconômico e também a relação já mencionada existente entre o contexto local e o global, parece-me pertinente aplicar o mesmo raciocínio dialético à experiência histórica e, em especial, à brasileira tal como apresentado por Schwarz em “Cultura e política, 1964-1969"10. No ensaio em questão, o autor realiza uma análise da conjuntura cultural e política do país, contemporânea à época da escrita do ensaio em que ele argumenta no sentido de mostrar que o que a modernização trouxe, de fato, foi a atualização de nossa tradição colonial ao invés da ruptura com ela, tal qual aparentava ser. Schwarz ressalta que não se trata de mera convivência de resquícios do passado ${ }^{11}$ com uma nova ordem, ilustrando o caráter constitutivo do passado nessa nova ordem por meio
9. XAVIER. O olhar e a voz: a narração multifocal do cinema e a cifra da História em São Bernardo, p. 129-130.

10. SCHWARZ. O pai de família outros ensaios, p. 70-111.

11. SCHWARZ. Cultura e política 1964-1969: Alguns esquemas, 
12. SCHWARZ. Cultura e política, 1964-1969: Alguns esquemas, $p$ 91.

13. SCHWARZ. Cultura e política, 1964-1969: Alguns esquemas, $p$ 82. da produção tropicalista: apesar de sua aparência vanguardista, ela só se firma como tal ao assumir as antigas desigualdades do país como a matéria brasileira por excelência Não há intenção de questioná-las, isto é, passa-se, segundo o autor, a endossar o status quo do mesmo modo como a elite o fazia por interesses óbvios. Reproduzindo a voz tropicalista Schwarz formula, como segue, a acomodação vigente: "nós, os atualizados, os articulados com o circuito do capital, falhada a tentativa de modernização social feita de cima, reconhecemos que o absurdo é a alma do país e a nossa" ${ }^{12}$. Assim aquilo que parecia superado em meio ao crescimento do país mostra sua permanência como foi - de modo surpreendente para a época - visto pelo autor, na "Marcha da Família com Deus, pela Liberdade”, que contou com a participação exatamente daqueles pertencentes ao "Brasil Moderno". E acrescenta, em tom de gracejo, a respeito do que ocorria na época: "curiosidades antigas vieram à luz, estimuladas pelo inquérito policial-militar que esquadrinhava a subversão. O professor de filosofia acredita em Deus? - O senhor sabe inteira a letra do Hino Nacional? - Mas as meninas, na faculdade, são virgens?" ${ }^{13}$

E é exatamente por meio de um olhar atento à forma objetiva da arte, como no caso da produção tropicalista, que Schwarz chega à compreensão do funcionamento da dinâmica social brasileira, uma vez que, as formas conteriam, retomando Adorno, "experiência histórica mesmo que nós não saibamos qual"14. O que reforça conclusões de estudos contemporâneos, realizados em outras áreas, como é o caso da Ciência Política com trabalhos como Os sentidos do lulismo ${ }^{15}$ de André Singer. Nessa obra, Singer designa como lulismo a política do governo Lula que conciliou uma melhora significativa na qualidade de vida da camada social subproletária com a preservação dos interesses da classe hegemônica. Mais uma vez, o que temos é a complementação daquilo que, a princípio, seria inconciliável. E essa constante não é recente. Ao retomar ainda outro processo de avanço social, podemos citar as observações do historiador Perry Anderson a respeito do processo ocorrido no Brasil no fim do século XIX ${ }^{16}$ Ele nos lembra de que a efetivação da abolição da escravatura só ocorreu quando ela não mais ameaçava a condição de vida dos proprietários. De todo modo, nesses casos todos, ao que parece, o que temos é aquilo que Schwarz resgata de Trotski, isto é, o "desenvolvimento desigual e combinado do capitalismo" ${ }^{17}$ que, por exemplo, se mostra em suas diversas manifestações no romance Memórias Póstumas de Brás Cubas de Machado de Assis.

Para argumentar nesse sentido, o crítico literário tratado aqui parte de uma análise cerrada do primeiro capítulo do romance e, de lá, extrai um padrão narrativo que é entendido como o do próprio funcionamento da sociedade. É assim
14. SCHWARZ. Por que 'ideias fora do lugar'?, p. 172.

15. SINGER. Os sentidos do lulismo p. 2012.

16. ANDERSON. Lula's Brazil, p. 12

7. SCHWARZ. Um mestre $n$ periferia do capitalismo, p. 39. 
18. SCHWARZ. Um mestre na periferia do capitalismo,p. 66.

19. SCHWARZ. Um mestre na periferia do capitalismo,p. 18

20. SCHWARZ. Um mestre na periferia do capitalismo, p. 223

21. SCHWARZ. Um mestre na periferia do capitalismo,p. 226 que ele se volta à importância do foco narrativo no romance que dá forma implícita ao conflito entre classes sociais e se alinha às ideias de seu tempo, situando-o, assim, em nossa tradição literária e na posição estrutural subalterna do país em relação à ordem mundial. Em sua obra Um mestre na periferia do capitalismo, o autor identifica como traço marcante do narrador, a volubilidade e como isso se espraia para todos os personagens e situações em que estão envolvidos. Ta afirmação se sustenta na análise do estilo narrativo escolhido e no modo pelo qual esse mesmo estilo se reproduz no próprio enredo do romance ${ }^{18}$, tendo, ao fim, como referente "a conduta própria à classe dominante brasileira" ${ }^{19}$. Em outras palavras, o estilo volúvel do narrador e dos personagens se configura como um modo de desviar a atenção daquilo que realmente importa, isto é, os interesses de classe. Segundo Schwarz, ao dar voz a um personagem pertencente à classe que detém o poder, Machado dá as pistas para o caráter cínico da polida elite brasileira e, para que fique clara a ideia, o crítico compara as distintas fases da escrita de Machado. Se volubilidade de tal elite já aparecia nos romances da primeira fase como conteúdo ${ }^{20}$, cuja abordagem buscava apontar por soluções construtivas, a segunda (e as Memórias póstumas é o primeiro exemplar disso) tratou de captar, em sua forma, a posição elitista e que claramente não apontava para "a superação da dependência pessoal pelo trabalho livre" ${ }^{21}$. E o curioso de tais percepções está no fato de elas terem lhe ocorrido "pouco antes de 1964" ${ }^{22}$. Quero dizer: foi o olhar atento à forma objetiva das manifestações artísticas - que não eram necessariamente contemporâneas ao autor - que lhe permitiu compreender como funcionava a sociedade brasileira sem que ainda o retrocesso tivesse se concretizado de fato, daí o motivo pelo qual a leitura crítica nos leva a pensar o momento presente e nos chama "à vida desperta" ${ }^{23}$

No entanto, uma crítica poderia ser levantada aqui. Como foi dito anteriormente, Schwarz se opõe à postura tropicalista de reconhecimento das contradições brasileiras, pois, como está colocada lá, essa postura levaria apenas a um alinhamento indireto com o conservadorismo. Desse modo não estaria o crítico invalidando seu posicionamento ao afirmar que "aos olhos do crítico dialético a fratura da forma aponta para impasses históricos" ${ }^{24}$ ? Isto é, Schwarz não estaria recaindo sobre o mesmo equívoco de fixar o Brasil num paradigma em que a miséria seria sempre necessária para a sua identidade? E a resposta negativa pode ser encontrad na explicitação do método do autor, indicado na conclusão de Um mestre na periferia: "ao invés do artista aprisionado em constrangimentos sociais [...] mostramos o seu esforço metódico e inteligente para captá-los, chegar-se a eles, lhe perceber a implicação e os assimilar como condicionantes da escrita, à qual conferem ossatura e peso reais" ${ }^{25}$. E aí está a diferença: enquanto o movimento tropicalista desistia de
22. SCHWARZ. Um mestre na periferia do capitalismo, p. 12

23. SCHWARZ. Um mestre na periferia do capitalismo, p. 242.

24. SCHWARZ. Um mestre na periferia do capitalismo, p. 171.

25. SCHWARZ. Um mestre na periferia do capitalismo, p. 241. 
26. WATT. Realism and the novel form, p. 9-37.

27. Tradução livre de: “[...] never in any previous civilization have the great metaphysical questions of being and of the meaning of life, seemed so utterly remote and pointlessly". "JAMESON. T.W. Adorno; or. HistoricalTropes, p. XVIII.

28. XAVIER. O olhar e a voz: a narração multifocal do cinem e a cifra da História em São

29. Tradução livre de: “[...] we inhabit a dream world of artificial stimuli and televised experience Historical Tropes, p. XVIII.
Hich

buscar saídas para esses impasses, preferindo celebrar o país do modo como se encontrava, a crítica de Schwarz se afast dessa celebração, o que pode ser o primeiro passo para uma intervenção efetiva em direção a uma mudança significativa.

Passando, então, de um romance do século XIX - cujo gênero se consolidou como o veículo de transmissão da experiência e das certezas do indivíduo burguês ${ }^{26}$ - a filmes brasileiros, um de meados do século XX e outro do início do XXI, encontramos mudanças nas manifestações culturais que se relacionam diretamente ao acompanhamento das alterações sociais e vice-versa. Se seguirmos o raciocínio do crítico cultural Fredric Jameson, encontraremos em suas palavras, agora sendo ele a se referir a Adorno, que "nunca em nenhuma civilização anterior as grandes preocupações metafísicas, as questões fundamentais do ser e do significado da vida pareceram tão completamente remotas e sem sentido" ${ }^{27}$. Daí, com Xavier, encaminharmos o raciocínio no sentido de que a linguagem verbal com sua necessária linearidade (por mais sofisticadas que sejam as técnicas empregadas nela) apresenta um limite que seria superado pela complexidade da justaposição de imagem e som no cinema ${ }^{28}$ constituindo, portanto, uma linguagem mais apta a trama narrativas no "mundo onírico de estímulos artificiais e experiências televisivas que habitamos" 29

Ao falar em "tramar narrativas", retomo a diferenciação de Xavier entre "fábula" (que se refere a "certa história contada, a certas personagens, a uma sequência de acontecimentos que se sucederam num determinado lugar (ou lugares) num intervalo de tempo"30) e "trama" (que diz respeito ao "modo como tal história e tais personagens aparecem para mim" ${ }^{31}$ ), acrescentando a esse último conceito a relação com o seu referente, ou seja, a sociedade. Chegamos assim, mais uma vez, à forma objetiva, estudada por Roberto Schwarz. E mesmo antes do mencionado artigo "Pressupostos, salvo engano, de 'Dialética da malandragem”' e da publicação de Um mestre na periferia do capitalismo, podemos já encontrar, implicitamente, o mesmo conceito posto em prática em "O cinema e Os Fuzis" de 1966.

Neste último ensaio, Schwarz inicia apontando o papel do cinema para o sistema econômico vigente e a importância da imagem para a indústria cultural ${ }^{32}$. Entende-se, pois, de saída, a relevância do filme tratado pelo autor. Pretendo mostrar a mesma relevância de $O$ som ao redor, a ser apresentado mais adiante. Mesmo não se inserindo no circuito comercial, contam, ambos, como condição de existência, com a própria indústria, o que não significa menos potencial crítico de tais obras. $\mathrm{O}$ trabalho realizado pela indústria pode se mostrar muito efetivo ao oferecer as condições necessárias para a sua própria crítica, de modo semelhante ao que vimos com o
30. XAVIER. Do texto ao filme: a trama, a cena e a construção do olhar no cinema, p. 65.

31. XAVIER. Do texto ao filme: a trama, a cena e a construção do Olhar no cinema, p. 65.

32. SCHWARZ "O cinema e Os Fuzis", p. 29. 
33. SCHWARZ. "O cinema e Os Fuzis", p. 30.

34. SCHWARZ. “O cinema e Os Fuzis", p. 32-33.

35. SCHWARZ. "O cinema e Os Fuzis", p. 33. narrador em primeira pessoa em Memórias Póstumas. No entanto, além desse primeiro aspecto, outro que poderia pôr em dúvida a qualidade de Os Fuzis é, segundo Schwarz, o fato de esse filme pertencer ao movimento do Cinema Novo, o que poderia significar a criação de uma inadequada proximidade entre narrativa e público. Essa relação de identidade, por sua vez, apagaria as diferenças entre a miséria representada e as condições de vida do espectador de classe média, levando, assim, à desconsideração do contexto da representação ${ }^{33}$. Mas, como continua o crítico, Ruy Guerra não erra neste ponto: "ao deslocar o centro dramático do retirante para a autoridade, o filme ganha muito, pois torna mais inteligível e articulada a sua matéria" ${ }^{34}$. Quer dizer, evita-se o apelo emotivo para não deslocar a atenção do espectador de uma apreciação crítica. No caso, se sentimos compaixão pelos miseráveis, a identificação com os soldados pode ocorrer devido ao que representam, isto é, protegem a propriedade privada. Ao mesmo tempo, não há como não ver os desmandos da tropa. O que leva o autor a concluir: "onde nos identificamos, desprezamos; de modo que a compaixão passa, necessariamente, pela destruição de nossos emissários, e, neles, de uma ordem de coisas" ${ }^{35}$. No entanto, a mudança não acontece de todo. Do mesmo modo que o autor havia identificado uma linha de força no romance de Machado (a desfaçatez de classe via volubilidade), no filme, Schwarz vê em ação uma forma entre movimento e inércia. A todo momento, a tensão aumenta, mas não se chega ao desfecho esperado até a sequência final em que um dos militares toma a iniciativa a favor dos miseráveis, embora esses mesmos não se unam à revolta, mantendo as coisas como estavam. A única reação do povo a que temos acesso é na cena final em que o boi santo é imolado. Aqueles que objetivamente privavam o povo se mantêm ilesos, ao passo que o suposto animal sagrado por não trazer a chuva, é imolado. Isto é, a mesma dinâmica social de então (1964) aparece transposta em narrativa ${ }^{36}$ Entretanto, quanto à forma objetiva, o autor irá alertar em Um mestre: "[...] em nenhum momento a correspondência entre comportamento narrativo e quadro social está afirmada [...] depende exclusivamente da percepção do leitor, e mesmo de seu ânimo de contrapor o próprio juízo ao do narrador $[. .].]^{37}$.

Então, voltando ao impasse entre movimento e inércia que, em Os Fuzis, encontra seu clímax no momento em que o chofer toma a iniciativa de se rebelar contra o carregamento de alimentos para venda enquanto a população local passa fome a ponto de um bebê morrer, Schwarz vê um possível problema: "se a crise é moral e o antagonismo é político, de que serve sua aproximação?" ${ }^{38}$. Realmente, numa leitura interna ao mundo narrado, o disparate pode soar como uma falha na trama narrativa, entretanto, contrapondo-se à ordem dada, Schwarz conclui: "serve, n’Os Fuzis, para marcar a
36. SCHWARZ. “O cinema e Os Fuzis", p. 31.

37. SCHWARZ, Um mestre na periferia do capitalismo, p. 173.

38. SCHWARZ, O cinema e Os Fuzis, p. 35.
EM TESE

BELO HORIZONTE

v. 21

N. 1

JAN.-ABR. 2015

SOSTER. Forma objetiva em Roberto Schwarz [...]

P. $87-100$ 
39. SCHWARZ, O cinema e Os Fuzis, p. 35.

40. SCHWARZ. Que horas são? Ensaios, p. 11 - 28.

41. SCHWARZ. A carroça, o bonde e o poeta modernista, p. 18.

42. SCHWARZ. Verdade Tropical: um percurso de nosso tempo, $\mathrm{p}$. $52-110$. descontinuidade. Noutras palavras, serve à crítica do moralismo, pois acentua tanto a responsabilidade moral quanto a sua insuficiência. O nexo importante, no caso, está na ausência de um nexo direto" ${ }^{39}$.

No mesmo sentido, é ainda possível lembrar-se de outros estudos do crítico em que se pode notar uma continuidade na própria descontinuidade. No ensaio "A carroça, o bonde e o poeta modernista" ${ }^{40}$, ao discutir o modernismo brasileiro da década de 30, Schwarz passa a analisar o poema "Pobre Alimária” de Oswald de Andrade e nele nota tanto a reação do motorneiro quanto do carroceiro ao tomarem para si os interesses dos advogados que se dirigiam para seus escritórios e como tal situação é caracterizada de modo cômico pelo próprio poeta. Novamente, a princípio, temos o disparate, mas diante do contexto sócio-histórico, a importância simbólica que se autoatribuem relaciona-se, mais uma vez, com nossa tradição patriarcal. Schwarz nos lembra: "o sujeito ativo e desimpedido da poesia vanguardista coexiste com a ânsia generalizada de reconhecimento superior, própria ao Ancien Régime das dependências pessoais, originário do período colonial" ${ }^{41}$

Ao que parece, ao passar aos anos 60, retomando à discussão de "Verdade Tropical: um percurso de nosso tempo"42, Schwarz observa um aspecto da dualidade brasileira em Terra em transe (Glauber Rocha, 1967) no episódio em que um personagem intelectual cala. com a mão. a boca de um popular. Sobre isso, afirma-se: "[o intelectual] se engaja na causa popular ao mesmo tempo que mantém as avaliações conservadoras [...] a respeito do povo" ${ }^{\prime 3}$. O contexto é outro se comparado a Os Fuzis, mas o impasse é o mesmo e o que chama atenção é a abordagem mais conformada, em contraste com o humor do tratamento dos anos 30. Como será mais detalhado adiante, tomando um exemplo contemporâneo, em O Som ao Redor (2012), o dado observado continua a ser a importância simbólica presente entre certos personagens como Luciene e Clodoaldo, respectivamente a empregada doméstica de um grande proprietário e um guarda noturno da rua em que mora o mesmo proprietário. Ao invés de se oporem como classe perante às mais altas, buscam, individualmente, saídas para uma aparente igualdade, seja pela oportunidade de ter uma relação sexual na cama de um "patrão", seja pela ostentação do uso do aparelho celular como garantia de um serviço de segurança eficiente. Tanto em Ruy Guerra, quanto em Mendonça Filho, as tensões que vão aparecendo não são levadas a uma transformação de fato, apenas asseguram a permanência do estado anterior de dependência.

Para Schwarz, em Os Fuzis, o que fica apenas é a "excitação e o movimento" ${ }^{44}$ após o sacrifício do boi, enquanto que em $O$ som, exceto a surpresa da última sequência,
43. SCHWARZ. Verdade Tropical: um percurso de nosso tempo, p. 76.

44. SCHWARZ. O cinema e Os Fuzis, p. 36. 
45. SCHWARZ. O cinema e Os Fuzis, p. 36. ficam as vinganças particulares de Clodoaldo e Bia que não se encaminham, de fato, para um desfecho satisfatório da tensão. Mas, ainda assim, em ambos os filmes, permanece o suspense do que ainda poderia acontecer. O processo se mantém em aberto, ainda que com sentidos distintos. No filme de Ruy Guerra, resta, como possibilidade, a ameaça, caso o povo direcionasse sua ação para quem realmente os prejudica $^{45}$, integrando, assim, o próprio desejo da época De modo distinto, o processo se converte, contemporaneamente, em frustração e cansaço ao vermos mais do mesmo tal qual ocorre no desfecho de $O$ som.

Nesse último filme, uma relação é estabelecida com seu início, quando nos são apresentadas fotografias do passado rural brasileiro que vaga entre referências à colônia até as lutas campesinas dos anos 60, acompanhadas, significativamente, de uma trilha sonora que se inicia com o que se assemelha a uma marcha fúnebre e passa a batuques, composição de Serge Gainsbourg, cujo título é "Cadavres en série". Inclusive ao notarmos o desenvolvimento de tais batuques que se iniciam com bumbos aos quais vão sendo acrescentados a castanhola, o chocalho, o pandeiro, a conga e o bongô, a tensão aumenta gradativamente a ponto de, ao beirar o mero ruído, um corte abrupto ocorre. No plano visual, somos transportados para o estacionamento de um condomínio de classe média, onde uma garota anda de patins e um garoto anda de bicicleta. A ruptura é evidente de uma situação para a outra tanto no plano visual quanto sonoro, já que agora o que se ouve é o martelar de um bate-estacas de alguma construção vizinha e, a princípio, o ruído dos patins, aos quais também são acrescentados outros ruídos da área de lazer. O som é outro, mas a cadência rítmica é a mesma. Quer dizer, para que a tensão da primeira sequência se mantivesse na segunda, foi necessária a ruptura. E esse aspecto formal observado no plano sonoro pode ser observado em muitas outras circunstâncias ao longo dessa narrativa fílmica como, por exemplo, na ruptura dos núcleos narrativos pela inserção de esquetes durante a primeira parte.

As situações são outras em comparação às de João, Bia, Clodoaldo entre outros protagonistas, mas a tensão social que as constitui é a mesma. Como exemplo, podemos citar o momento em que Bia recebe sua nova televisão em casa. Apesar de sua polidez com os entregadores, é possível notar sua sutil impaciência no momento em que não é compreendida quanto ao modo que deseja que o aparelho seja colocado na sala, impaciência devido ao seu nervosismo após ter sido fisicamente atacada pela irmã. Na sequência, o esquete da mulher que sai da clínica de acupuntura (a câmera é clara ao focalizar sua orelha cheia de esparadrapos com sementes de mostarda). Mesmo após um tratamento tranquilizante (o que poderia ser lido como uma saída para o próprio nervosismo 
46. SCHWARZ. O cinema e Os Fuzis, p. 33.

47. Idem, Um mestre na periferia do capitalismo, p. 30. de Bia), a mulher acaba por maltratar guardadores de carro, na verdade, revelando seu gosto pelo mandonismo (o que se reproduz, no comportamento de Bia, quando sua empregada queima seu aparelho inibidor de latidos). Isto é, aos poucos, $O$ som vai se formando explicitamente não como a narrativa específica de certos personagens, mas como a narrativa de uma dada classe social, dado também presente no próprio foco narrativo, como procuro mostrar em seguida.

Como é possível observar em diversos momentos, a narrativa também é dada a partir do ponto de vista da classe média. Basta atentar para o momento em que João encontra o filho de sua empregada dormindo em seu sofá. A câmera não se encontra na sala, mas atrás de João. Um outro exemplo é o dos entregadores que chegam com o televisor de Bia. Não esperamos Bia com os entregadores. Vamos com ela até eles, traço semelhante ao encontrado em Os Fuzis que também confere atenção aos militares que não são nem grandes proprietários (em $O$ som, poderíamos pensar em Francisco, mas esse já encontra seu poderio em decadência), nem miseráveis ${ }^{46}$. Entretanto, mesmo que a experiência registrada pertença à camada mediana, as regras pelas quais operam são as da elite (tal como no caso do poema de Oswald de Andrade) que buscaria, como se pode conferir também em Memórias Póstumas: "uma supremacia qualquer que fosse" ${ }^{47}$. A respeito dos soldados de Os Fuzis, Schwarz é categórico: "mandam, mas são mandados; se olham para baixo são autoridades se olham para cima são povo também" ${ }^{48}$. Comportamento semelhante pode ser visto em personagens do filme de Mendonça Filho tal como nos são apresentados os guardas noturnos que se posicionam como tendo maior importância do que realmente têm e até mesmo pelo narrador. Se, por um lado, as constantes rupturas mostram certa superioridade em relação ao público, pois é ele a decidir até que ponto nos revelar o que está de fato acontecendo; por outro, sua forma é condicionada à própria percepção contemporânea do mundo, cujos fragmentos parecem indicar a superação de um passado que insiste em se marcar a todo o momento no presente segundo a organização contemporânea do capita (ou seja, a volubilidade e a conjugação entre inércia e movimento ainda persistem, ressignificadas). E isso claramente não tranquiliza, as situações de tensão são uma constante $\mathrm{nO}$ som que crescem e se dispersam repentinamente sem apresentar um desfecho que resolva a tensão de modo semelhante ao que acontecia em Os Fuzis em que "a massa dos miseráveis fermenta, mas não explode" ${ }^{49}$ (com a diferença de que no último filme, se há explosão, seu resultado é incerto).

Além disso, um modo possível de articular, numa abordagem sócio-histórica, a continuidade na ruptura é compreendê-la como articulada entre dois modos distintos de relação com o mundo, um via memória e outro via nostalgia. Para
48. SCHWARZ. O cinema e Os Fuzis, p. 33

49. SCHWARZ. O cinema e Os Fuzis, p. 31.

BELO HORIZONTE

v. 21

N. 1

JAN.-ABR. 2015

SOSTER. Forma objetiva em Roberto Schwarz [...]

P. $87-100$ 
50. SOSTER. Relações entre memória e nostalgia: o conflito pela ocupação do espaço em $O$ som ao redor, p. 1-10.

51. BRACKE. From politics to nostalgia: the transformation of war memories in France during 1960s-1970s, p. 6.

52. SCHWARZ. Um mestre na periferia do capitalismo, p. 241.

53. BOYM. The nostalgia of the future, p. 3-4. defini-los, retomo trabalho anterior ${ }^{50}$ em que já me ocupei em distingui-los. Quando digo "memória”, refiro-me a uma relação com o presente em que o passado é patente no $e$, aqui e agora. No âmbito social, é "um espaço de poder e conflito sociopolítico" 51 portanto, com potencial de alteração do status quo (é o que confere "peso e ossatura reais" 52 , como já mencionado, às narrativas). Já para definir uma acepção para nostalgia, parto dos estudos de Svetlana Boym que se iniciam pela definição etimológica da palavra que é formada por dois radicais gregos: nostos, retorno ao lar, e algia, desejo $^{53}$. Quer dizer, se é, a princípio, o desejo de retorno ao lar entende-se que não se está onde quer. É um sentimento de deslocamento que pode ser aplicado não só ao espaço, mas também ao tempo. E mais do que isso, é a idealização de que esse outro espaço e tempo sejam melhores do que aqueles em que se está. A ruptura é inerente a ela e se, há alguma perspectiva, levando em consideração o eixo temporal, ela está na repetição do passado no futuro. Posto isso e, em coerência com o que vimos apresentando, não poderíamo manter tais conceitos em oposição, mas numa relação em que a memória seja sustentada pela nostalgia e vice-versa. Alguns exemplos: retomando o poema "Pobre Alimária" de Oswald de Andrade, é por meio da representação de carroceiros, motorneiros e advogados, os quais idealizam uma identidade que proceda simbolicamente apesar de suas condições materiais, ou ainda, é por meio de uma representação de uma experiência nostálgica do sistema escravocrata que nós, leitores, chegamos a reconstituir a memória da sociedade brasileira; em Os Fuzis, o líder espiritual do povo, que abre a narrativa, retoma os tempos míticos das narrativas bíblicas para explicar a miséria presente, apesar da real exploração da qual eram objeto. Assim, a sequência final é responsável por ativar uma relação com o tempo presente de modo a indicar o que de fato ocorreria caso a fúria fosse direcionada a quem materialmente os prejudica; já em $O$ som, a memória surge completa para os espectadores quando o personagem Clodoaldo só vê uma alternativa: agir nos moldes nostálgicos por meio da vingança, matando Francisco, assassino de seu pai, morto por uma disputa de terras. É importante constar que, seja o povo de os Fuzis, seja Clodoaldo, ambos estão sujeitos às formas objetivas de suas narrativas, o que impõe certos limites a suas ações.

Outro modo possível de entender como podem relacionar-se memória e nostalgia é partir da ideia de que a memória estabelece uma continuidade diante da dispersão de fatos, ela se materializa em forma de narrativas. Enquanto isso, o mundo se apresenta de modo a dar a impressão de que a experiência contemporânea se dá de modo independente do passado. Na produção de Mendonça Filho, apesar da apresentação das situações cotidianas de classe média, a história age e vamos entrando em contato com ela à medida 
54. JAMESON. Cognitive mapping, p. 277-287.

55. JAMESON. Cognitive mapping," p. 283. que a narrativa se desenvolve. Até chegarmos ao seu final, momento em que compreendemos claramente a ligação do passado do país com nosso presente, ainda que os próprios personagens não tenham clareza disso. Portanto, resumindo a linha em que temos trabalhado: a forma objetiva identificada por Schwarz no romance machadiano nos revela o caráter da elite brasileira e como ele serve de matriz para as demais classes. No poema de Oswald, é trazida, numa abordagem cômica, uma série de compensações simbólicas. Essa idealização, nos anos 60, passa por Ruy Guerra como o desejo por mudanças as quais, no entanto, não se concretizam ou, ao menos, não se concretizam do modo esperado, o que nos leva ao jogo entre memória e nostalgia tal qual em $O$ som ao redor.

Com o intuito de trazer para a discussão a questão de que esse modo de lidar com as produções artísticas não é exclusivo de um crítico brasileiro e que também é pensada por intelectuais situados nos centros hegemônicos, retomo o conceito de "mapeamento cognitivo", elaborado por Fredric Jameson ${ }^{54}$, Segundo o autor, esse conceito busca a totalidade da estrutura social com o principal objetivo de elaborar um projeto político socialista ${ }^{55}$. É desse modo, portanto, que, assim como Schwarz, o crítico norte-americano avalia o preço que se paga para se gozar da sensação de bem estar propagada pelos que defendem a possibilidade de um presente livre de passado ou mesmo de um passado que guardaria um presente ideal. É com o intuito de buscar aquilo que escapa ao discurso do centro que se propõe a realização de um mapeamento cognitivo de determinada obra, pois, a exemplo da forma objetiva, é por meio dele que se compreende a relação de determinada produção cultural e a sociedade, assim como os limites aparentes de compreensão produzidos. Em relação à sua análise do filme hollywoodiano Dog Day Afternoon (Sidney Lumet, 1975), Jameson afirma: “[...] o sistema de classes que temos discutido está meramente implícito nele e pode ser tão facilmente ignorado ou reprimido pelos seus espectadores quanto trazido à consciência" ${ }^{56}$. A relação com o que afirma Schwarz em Um mestre na periferia do capitalismo parece ser inevitável ${ }^{57}$.

Essa semelhança entre pensadores de uma mesma geração, mas de origens bem distintas nos faz pensar que algo da própria conjuntura mundial capitalista leva a uma intuição semelhante, o que é por si a atuação da própria forma objetiva. Semelhanças à parte, é também necessário sempre levar em conta que a posição defendida por Schwarz é marcada pela diferença com o centro: "ao fincar o pé na condição periférica, o crítico periférico está pondo em evidência um aspecto da sociedade contemporânea que, na construção dos países centrais, que são universalistas, desaparece" ${ }^{58}$. Em outras palavras, não é possível colocar-se de igual para igual como parece
56. JAMESON. Class and allegory in contemporary mass culture, p. 304. Tradução livre de: "[...] the class system we have been taking a implicit in it, and can just as Implicit in it, and can just as by its vigners as brought to .

57. SCHWARZ. Um mestre na periferia do capitalismo, p. 173.

58. SCHWARZ. A dialética da formação, p. 185. 
59. SCHWARZ. A dialética da formação, p. 185.

60. SCHWARZ. A poesia envenenada de Dom Casmurro, p. 40.

61. SCHWARZ. Por que 'ideias fora do lugar'?, p. 171. ser a prática corriqueira de parte da crítica tal como é afirmado em certa passagem: "O normal de um intelectual ambicioso no Brasil é falar do mundo, falar como um filósofo para o qual existe o mundo e não existe a distinção centro e periferia" 59 o que não significa que a crítica vinda da periferia seja necessariamente inferior, visto que, mais uma vez, como ele bem sintetiza: "a inferioridade do país é inegável, mas a superioridade de nossos modelos não convence" ${ }^{60}$.

Ao que tudo indica, portanto, só quando a memória vem à tona, como as análises de Memórias Póstumas de Brás Cubas, "Pobre Alimária", Os Fuzis e $O$ som ao redor demonstram, que podemos, de fato, nos aproximar de suas respectivas formas objetivas. E isso passa necessariamente pelo reconhecimento de que "relações de hegemonia existem, e desconhecê-las [...] é por sua vez uma resposta fora do lugar" ${ }^{61}$.

\section{REFERÊNCIAS}

ANDERSON, Perry. Lula's Brazil. In: London Review of Books vol. 33, n 7, 31. Março 2011, p. 3-12.

BOYM, Svetlana. The nostalgia of the future. New York: Basic Books, 2001

BRACKE, Maud. From politics to nostalgia: the transformation of war memories in France during the 1960s-1970s. In: European History Quarterly, vol. 41, n 5, p.5-24, fevereiro, 2011. Disponível em: <http:/ ehq.sagepub.com/content/41/1/5>. Acesso em: 23 set. 2014.
JAMESON, Fredric. T. W. Adorno; or, Historical Tropes. In: JAMESON, Fredric. Marxism and form. Princeton: Princeton University Press, 2013, p. 3-59.

JAMESON, Fredric. Cognitive mapping; Class and allegory in contemporary mass culture: Dog Day Afternoon as a political film. In: HARDT, Michael; WEEKS, Kathi. The Jameson Reader. Hoboken: Blackwell Publishing, 2000, p. 277-287; 287-307.

JAMESON, Fredric. Culture and finance capital. In: Critical inquiry, vol. 24, no 1, Outrono 1997, p. 136-161.

SCHWARZ, Roberto. Verdade Tropical: um percurso de nosso tempo; Por que 'ideias fora do lugar?'. In: SCHWARZ, Roberto. Martinha versus Lucrécia: ensaios e entrevistas. São Paulo:

Companhia das Letras, 2012a, p. 52-110: 165-172.

SCHWARZ, Roberto. Um mestre na periferia do capitalismo. $5^{a}$ ed. São Paulo: Duas Cidades; Editora 34, 2012b.

SCHWARZ, Roberto. Ao vencedor as batatas. $6^{\mathrm{a}}$ ed. São Paulo: Duas Cidades; Editora 34, 2012c.

SCHWARZ, Roberto. A carroça, o bonde e o poeta modernista. Pressupostos, salvo engano, de "Dialética da Malandragem". In: SCHWARZ, Roberto Que horas são?: ensaios. $2^{\mathrm{a}}$ ed. São Paulo: Companhia das Letras, 2012d, p. 11-28; 129-155.

SCHWARZ, Roberto. A dialética da formação. In: PUCCI, Bruno ALMEIDA, Jorge de; LASTÓRIA, Luiz A. Calmon Nabuco. Experiência formativa e emancipação. São Paulo: Nankin editorial, 2009, p. 163-186. 
SCHWARZ, Roberto. O cinema e Os Fuzis; Cultura e política

1964-1969: alguns esquemas. In: SCHWARZ, Roberto. O pai

de família e outros estudos. São Paulo: Companhia das Letras,

2008, p. 29-36: 70-111.

SCHWARZ, Roberto. A poesia envenenada de Dom Casmurro. In SCHWARZ, Roberto. Duas Meninas. São Paulo: Companhia das Letras, 1997, p. 9-41.

SCHWARZ, Roberto. Adequação nacional e originalidade crítica. In: SCHWARZ, Roberto. Sequências brasileiras. São Paulo: Companhia das Letras, 1994 , p. 24-45.

SINGER, André. Os sentidos do lulismo. São Paulo: Companhia das Letras, 2012.

SOSTER, Vitor. Relações entre memória e nostalgia: o conflito pela ocupação do espaço em $\mathrm{O}$ som ao redor. In: I Seminário Gêneros Híbridos da Modernidade e I Simpósio memória e representação literária, 2014, Assis, Anais, 10p. (no prelo).

XAVIER, Ismail Norberto. Do texto ao filme: a trama, a cena e a construção do olhar no cinema. In: CAMARGO, Luis. Literatura, cinema e televisão. São Paulo: Editora SENAC, 2003, p. 61-89.

XAVIER, Ismail Norberto. O olhar e a voz: a narração multifocal do cinema e a cifra da História em São Bernardo. In: Literatura e sociedade, São Paulo, vol. 2, 1997, p. 126-138.

WATT, lan. Realism and the novel form. In: WATT, lan. The rise of the novel: studies in Defoe, Richardson and Fielding. $2^{\mathrm{a}}$ ed. Berkley e Los Angeles: University of California Press, 2001, p. 9-37. 